\title{
Post partum heart failure: a rare presentation to the intensive care unit of a teaching hospital in Ghana
}

This article was published in the following Dove Press journal:

International Medical Case Reports Journal

3I May 2012

Number of times this article has been viewed

\author{
Isaac Kofi Owusu' \\ Charles Anane' \\ Kwame Ohene Buabeng ${ }^{2}$ \\ 'Komfo Anokye Teaching Hospital, \\ ${ }^{2}$ Clinical and Social Pharmacy \\ Department, Kwame Nkrumah \\ University Of Science and Technology, \\ Kumasi, Ghana
}

\begin{abstract}
A patient with a devastating form of heart failure that sometimes afflicts women in late pregnancy or after delivery presented to the intensive care unit of the Komfo Anokye Teaching Hospital, Kumasi, Ghana, in September 2010. The patient was a 37-year-old farmer and mother of six children, and was admitted with symptoms of heart failure five months after the delivery of her last child. After clinical evaluation, post partum cardiomyopathy was diagnosed. She responded well to treatment and was discharged on day 10 following admission, to be followed up at the cardiac clinic.
\end{abstract}

Keywords: heart failure, cardiomyopathy, late pregnancy, post partum, Ghana

\section{Introduction}

Heart failure has been defined as a clinical syndrome characterized by the functional inability of the ventricle to provide adequate perfusion to meet the metabolic demands of the body, resulting in symptoms of congestion or hypoperfusion. Post partum onset of heart failure has been recognized for more than 100 years, ${ }^{1}$ and is known as peripartum or post partum cardiomyopathy, but the etiology is poorly understood. This disorder is estimated to complicate one in every 1300-4000 deliveries in the US, and is considered to be among the leading causes of death among post partum women in industrialized countries. It is also reported to be the most frequent clinical form of heart failure in women hospitalized in Sudanese-Sahelian Africa ${ }^{2}$ and in Nigeria. ${ }^{3,4}$ However, there are limited data on the disorder in Ghana. Risk factors include obesity and a history of cardiac disorders such as myocarditis, as well as smoking, alcohol abuse, multiple pregnancies, being African or black, and malnutrition. ${ }^{1}$

Post partum cardiomyopathy is said to be present when the disorder meets the following criteria: development of heart failure in the last trimester of pregnancy or within 5 months of delivery; absence of another identifiable cause for heart failure; absence of recognizable heart disease prior to the last month of pregnancy; and the presence of left ventricular systolic dysfunction with an ejection fraction $<45 \%$. The left ventricle may not be dilated, but the ejection fraction is nearly always reduced to below $45 \%$. ${ }^{1}$ Over $50 \%$ of patients show complete or near complete recovery within the first 6 months post partum. In others, there is either continued clinical deterioration leading to early death or persistent left ventricular dysfunction and chronic heart failure.

The exact cause is unknown, but autoimmune diseases, especially autoimmune thyroid disease, which frequently develops after delivery, have been implicated.
Correspondence: Charles Anane Department of Pharmacy, Clinical Pharmacy Office Komfo Anokye Teaching Hospital P.O. Box 1934 Kumasi. Ghana West Africa

Tel +0233020 I 313803

Fax +0233322061535

Email chaanane2005@yahoo.com 
Other proposed etiologies include low selenium levels and various viral infections. Others have suggested a genetic origin for the condition. ${ }^{1,3}$ It is also possible that cardiomyopathy which develops in the last month of pregnancy results from unmasking of previously undiagnosed heart disease by the hemodynamic stress of pregnancy. Advanced maternal age and multiparity have been noted as important risk factors. ${ }^{3}$ It has been reported more often in twin gestations and in women with pre-eclampsia, but both of these conditions are associated with a lower serum oncotic pressure that can predispose to noncardiogenic pulmonary edema in the setting of other stressors. Other findings associated with post partum cardiomyopathy, but not clearly causal, include increased markers of inflammation and oxidative stress. There are many risk factors associated with the disorder, including obesity and a personal history of cardiac disorders, such as myocarditis, as well as smoking, alcoholism during pregnancy, and malnutrition. ${ }^{1-4}$

\section{Case report}

A 37-year-old farmer was admitted to the obstetrics and gynecology department of the Komfo Anokye Teaching Hospital, Kumasi, Ghana, in April 2010, and spontaneously delivered her sixth baby at 32 weeks and 6 days of gestation. The patient was married and lived with her husband and five children. After a day in hospital, the patient was discharged home without any complaint. Five months after delivery, she was readmitted to the intensive care unit in the Department of Medicine, Komfo Anokye Teaching Hospital, Kumasi, with symptoms of acute heart failure of three weeks' duration. She had pedal swelling up to the knee, exertional dyspnea, orthopnea, and paroxysmal nocturnal dyspnea. She had no past history of hypertension or diabetes mellitus, or any known heart disease. She did not smoke cigarettes or drink alcohol.

On examination she looked generally unwell, was dyspneic at rest (New York Heart Association class IV), and had bilateral pitting pedal edema up to the knee. Her blood pressure on admission was $72 / 50 \mathrm{mmHg}$ and her pulse rate was 110 beats per minute, regular, and of small volume. The apex beat was diffuse and the jugular venous pressure was raised. Auscultation revealed an S3 gallop, but no murmur was heard. Her respiratory rate was 32 cycles per minute. Chest auscultation revealed bilateral basal crepitations, and the abdomen revealed pulsatile tender hepatomegaly with a liver span of $13 \mathrm{~cm}$ and ascites.

A 12-lead electrocardiogram showed sinus tachycardia of 116 per minute, right axis deviation, poor $\mathrm{R}$ wave progression, and nonspecific STT changes. The chest X-ray showed cardiomegaly (cardiothoracic ratio 0.78) and upper lobe blood diversion. Echocardiography showed dilated cardiac chambers with global left ventricular hypokinesis, left ventricular ejection fraction $<30 \%$, and a restrictive flow pattern. A full blood count showed a hemoglobin of $9 \mathrm{~g} / \mathrm{dL}$, and normal white cell and platelet counts. Blood biochemistry showed hepatic dysfunction and renal insufficiency. Aspartate aminotransferase, alanine aminotransferase, lactate hydrogenase, and total bilirubin were 314, 237, and 580 IU/L and $42.9 \mathrm{~mol} / \mathrm{L}$, respectively. An increase in creatine phosphokinase (943 IU/L) was also noted. A diagnosis of heart failure (New York Heart Association class IV) from post partum cardiomyopathy was made.

The patient was given intravenous dobutamine $250 \mathrm{mg} / 12$ hours and intravenous furosemide $240 \mathrm{mg} / 12$ hours via infusion pump, as well as oxygen at $4 \mathrm{~L}$ per minute. Digoxin $0.25 \mathrm{mg} /$ day orally and enoxaparin $40 \mathrm{mg} /$ day subcutaneously were also administered. She was given spironolactone $25 \mathrm{mg}$ orally on alternate days. A betablocker, carvedilol $3.125 \mathrm{mg}$ bid orally, and an angiotensinconverting enzyme inhibitor, lisinopril $2.5 \mathrm{mg} /$ day orally, were initiated after the patient was stabilized.

Ten days after admission, signs of congestive heart failure and liver and kidney dysfunction were markedly improved after the standard treatment described above. Her blood pressure increased to $100 / 70 \mathrm{mmHg}$ and her heart rate was 78 beats per minute. She responded well to treatment and was discharged on day 10 after admission. Her functional status had improved to New York Heart Association class II, left ventricular size was normalized, and ejection fraction had increased to $50 \%$. She is now being followed up at the cardiac clinic, Komfo Anokye Teaching Hospital, Kumasi.

\section{Discussion}

Despite its low incidence, peripartum cardiomyopathy has been described in many parts of Africa, ${ }^{2-5}$ and especially in Nigeria. ${ }^{3,4}$ Our patient complained of easy fatigability, palpitations, dyspnea, and pedal swelling up to the knee or five months after delivery. Even though many women develop pedal swelling and fatigue during the last trimester of pregnancy due to physiological changes, our patient had other severe symptoms of heart failure, including orthopnea and paroxysmal nocturnal dyspnea. A diagnosis of post partum cardiomyopathy was finally established and confirmed by echocardiography.

Because the incidence of post partum cardiomyopathy is low and the symptoms are nonspecific, diagnosis can often 
be delayed and may even be missed unless echocardiography is performed. The treatment given to our patient included a diuretic and carvedilol, a third-generation beta-adrenergic blocking agent, with the vasodilatory property of reducing afterload. Angiotensin-converting enzyme inhibitors are contraindicated during pregnancy due to potential teratogenic effects on the fetus, but can be given after delivery. It must be noted that the patient had to stop breastfeeding because of her poor state of health during the ten days admission at the hospital.

Our patient achieved normalization of left ventricular size and function within six months. It is possible that patients who have recovered from post partum cardiomyopathy and regain normal left ventricular size and function will still have depressed contractile ventricular function when subjected to the hemodynamic stress of pregnancy. Future pregnancy is not recommended in women with persistent ventricular dysfunction due to concerns about the ability of the dysfunctional heart to handle the increased cardiovascular workload during pregnancy. It is possible that postpartum cardiomyopathy which develops after delivery is the result of unmasking of previously undiagnosed heart disease by the hemodynamic stress of pregnancy.

\section{Conclusion}

Although post partum cardiomyopathy can be fatal, patients can lead normal lives after recovery with proper management and counseling. Patients who achieve full recovery should be told that while a chance of recurrence exists, the mortality rate is low and the majority of such women have normal pregnancies. Pregnancy is not recommended for women with persistent left ventricular dysfunction. Women with a persistently abnormal left ventricular ejection fraction are at high risk of developing heart failure and worsening cardiac function if they become pregnant again. The beta-blocker, carvedilol, in conjunction with conventional heart failure therapy, has improved the survival of women with post partum cardiomyopathy, and the need for such women to undergo heart transplantation has decreased by $34 \%$.

\section{Disclosure}

The authors report no conflicts of interest in this work.

\section{References}

1. Sliwa K, Hilfiker-Kleimer D, Petrie MC, et al. Current state of knowledge on aetiology, diagnosis, management and therapy of peripartum cardiomyopathy: a position statement for the Heart Failure Association of the European Society of Cardiology Working Group on peripartum cardiomyopathy. Eur J Heart Fail. 2010;12(8):767-778.

2. Kane A, Dia AA, Diop IB, Sarr M, Ba SA, Diouf SM. Peripartum heart failure: the underestimated role of frequent diseases in the Sudan-Sahelian area. Dakar Med. 2000;45(2):131-133. French.

3. Isezuo SA, Abubakar SA. Epidemiologic profile of peripartum cardiomyopathy in a tertiary care hospital. Ethn Dis. 2007;17(2): 228-233.

4. Karaye KM, Sai'du H, Habib AG. Peripartum and other cardiomyopathies in a Nigerian adult population. Int J Cardiol. 2011;147(2): 342-343.

5. Owusu IK. Causes of heart failure as seen in Kumasi, Ghana. The Internet Journal of Third World Medicine. 2007;5:1:1538-4646.
International Medical Case Reports Journal

\section{Publish your work in this journal}

The International Medical Case Reports Journal is an international, peer-reviewed open-access journal publishing original case reports from all medical specialties. Previously unpublished medical posters are also accepted relating to any area of clinical or preclinical science. Submissions should not normally exceed 2,000 words or

\section{Dovepress}

4 published pages including figures, diagrams and references. The manuscript management system is completely online and includes a very quick and fair peer-review system, which is all easy to use. Visit http://www.dovepress.com/testimonials.php to read real quotes from published authors. 